\title{
A Monte Carlo Revisiting of N-Methylformamide and Acetone
}

\author{
Glauco G. Almeida and João M. M. Cordeiro* \\ Departamento de Física e Química, Universidade Estadual Paulista, Av. Brasil, 56, \\ 15385-000 Ilha Solteira-SP, Brazil
}

\begin{abstract}
Os líquidos N-metilformamida e acetona foram revisitados através de simulações Monte Carlo feitas no ensemble NPT, a 1 atm e $25{ }^{\circ} \mathrm{C}$. As moléculas são rígidas com todos os átomos explicitados e o potencial intermolecular utilizado é o clássico 6-12 Lennard-Jones mais Coulomb. Os g(r)'s teóricos dos dois líquidos foram comparados com aqueles obtidos através de difratometria de nêutrons e simulação de refinamento de estrutura. Os resultados indicam a existência de ligações de hidrogênio determinando a estrutura da $\mathrm{N}$-metilformamida, enquanto que na acetona as correlações são orientadas pelo momento dipolar. A estrutura do líquido N-metilformamida é guiada por um dímero preponderante, no qual as moléculas estão posicionadas de maneira que o ângulo entre os vetores de dipolo é $73^{\circ}$, enquanto que no líquido acetona, que é muito menos organizado, a orientação dos dipolos das moléculas muda de antiparalela a curtas distâncias para mais paralela à medida que a distância aumenta.
\end{abstract}

The pure liquids $\mathrm{N}$-methylformamide and acetone have been revisited via Monte Carlo simulations in the NTP ensemble at $1 \mathrm{~atm}$ and $25^{\circ} \mathrm{C}$. The molecules are all-atom rigid structures, and the intermolecular potential used is the classical 6-12 Lennard-Jones plus Coulomb. The theoretical $\mathrm{g}(\mathrm{r}) \mathrm{s}$ of both liquids were compared with those obtained from neutron diffraction and empirical potential structure refinement simulations. The results point to the existence of $\mathrm{H}$-bonds driving the $\mathrm{N}$-methylformamide structure, while in acetone the correlations are dipole moment oriented. The structure of the liquid $\mathrm{N}$-methylformamide is mainly guided by a dimer whose molecules are arranged in such a way that the angle between their dipole moments is $73^{\circ}$, while liquid acetone is much less organized and the orientation of the molecules changes from an antiparallel dipolar correlation at short distances to more parallel alignments of the molecular dipole moments for larger distances.

Keywords: Monte Carlo, acetone, N-methylformamide, hydrogen bonds, liquid structure

\section{Introduction}

$\mathrm{N}$-methylformamide (NMF) and acetone (ACT) belong to a group of dipolar organic solvents, which are common media for a variety of important chemical reactions. Table 1 shows some of the most common physical-chemistry properties of the liquids to give an idea of the differences.

NMF is one of the simplest molecules among those that include a peptide bond in their structure. The molecule has long been of great interest because of the presence of that structure as a repeat unit in proteins and peptides. The liquid, either pure or as a component of mixtures, has been the subject of studies, theoretically ${ }^{2-10}$ as well as experimentally. ${ }^{11-18}$ The NMF molecules act as proton donors and acceptors via their $\mathrm{C}=\mathrm{O}$ and $\mathrm{H}-\mathrm{N}$

*e-mail: cordeiro@dfq.feis.unesp.br groups and consequently form $\mathrm{C}=\mathrm{O} \cdots \mathrm{H}-\mathrm{N}$ hydrogen bonds (H-bond) with each other, the same type of $\mathrm{H}$-bond that is known to play an important role in stabilizing the ordered intramolecular structure of peptides and proteins. ${ }^{19}$ Moreover, these molecules could also form weak $\mathrm{C}-\mathrm{H} \cdots \mathrm{O}=\mathrm{C}$ H-bonds, which might be important in stabilizing many systems, as extensively reported. ${ }^{20}$ In the pure liquid, molecules are hydrogen bonded to each other, leading to the formation of molecular chains throughout the liquid bulk, ${ }^{13}$ which must be in the origin of the large values of its properties (see Table 1).

Pure liquid ACT and some of its mixtures with other liquids have received a great deal of attention by diffraction as well as computational simulation..$^{21-33}$ ACT has a triangular planar shape $\left(\mathrm{C}_{2 \mathrm{v}}\right.$ geometry $)$ with the central carbon on the geometric center of the triangle. The liquid is weakly structured, which is reflected in the small values 
Table 1. Experimental values of some properties of the studied liquids

\begin{tabular}{lcccccc}
\hline Liquid & $\varepsilon$ & $\mu / \mathrm{D}$ & $\mathrm{BP} /{ }^{\circ} \mathrm{C}$ & $\Delta_{\text {vap }} \mathrm{H} /\left(\mathrm{kcal} \mathrm{mol}^{-1}\right)$ & $\Delta_{\text {vap }} \mathrm{S} / \mathrm{cal}(\mathrm{mol} \mathrm{K})^{-1}$ & $\left.\rho /(\mathrm{g} \mathrm{cm})^{-3}\right)$ \\
\hline NMF & 182 & 3.86 & 199.5 & 13.77 & 29.13 & 1.00 \\
ACT & 20.7 & 2.88 & 56.5 & 7.40 & 22.45 & 0.78 \\
\hline
\end{tabular}

$\varepsilon$ : dielectric constant; $\mu$ : dipole moment; BP: boiling point; $\Delta_{\text {vap }} \mathrm{H}$ : heat of vaporization; $\Delta_{\text {vap }} \mathrm{S}$ : entropy of vaporization; $\rho$ : density. The values can be found in Lide. ${ }^{1}$

of the properties listed in Table 1. The dipole interaction among the molecules plays an important role in the liquid structure. The liquid shows a predominance of antiparallel alignments of molecular dipole moments at short distances, while at larger distances the alignments become more parallel, and the molecules adopt more of a head-to-tail configuration. $.^{24,33} \mathrm{The} \mathrm{C}=\mathrm{O}$ group acts as a proton acceptor, rendering the $\mathrm{H}$-bond formation with proton donor molecules possible, and the two $\mathrm{CH}_{3}$ groups can originate hydrophobic effects when in aqueous solution. ${ }^{21}$

Studying enzymatic stability and activity in nonaqueous medium is very important due to the substantial implications regarding basic enzyme science, and because of the wide range of potential applications..$^{34,35}$ Experiments show that proteins are able to maintain their structure in many organic solvents and remain catalytically active. ${ }^{36-38}$ Thus, enzymology in non-aqueous media has received much attention, and many of the influences to the behavior of enzymes in nonaqueous solvents are now known. ${ }^{39-45}$ Notwithstanding, as this is a new field of study, many points remain to be clarified concerning the molecular events occurring in enzymes when performing catalysis under non-aqueous conditions.

Experimental structural investigations of proteins dissolved in organic solvents are generally difficult. ${ }^{46}$ Molecular simulation methods are powerful tools for investigating molecular interactions, reaction mechanisms, and dynamics of molecular solvation. In the case of enzymes, however, it is difficult to start by looking into the real systems, due to the great computational effort required to simulate such a system. ${ }^{47}$ Therefore, computationally simpler systems are commonly used in order to investigate a particular feature of an interesting system, and the acquired knowledge is extended to the actual system. That is the motivation behind the investigation of the liquids NMF and ACT. The first is a good model for the peptide bond in peptides and proteins and the second an interesting organic solvent to investigate enzymatic activity in non-aqueous media. The mixture of the two liquids may be investigated in the future; however, to obtain detailed understanding of the role of a liquid in different chemical systems and environments, modeling the pure solvent and studying its structure are essential.
The problem of extracting reliable structural information about molecular arrangement and orientation experimentally in relatively simple molecular fluids such as the present examples is well known. ${ }^{48}$ Computational simulations are very useful techniques for studying the structure of molecular liquids since detailed radial distribution functions (rdf) of the liquids can be obtained. The insights given by site-site correlation functions calculated by computer simulations can be very useful in interpreting the liquid structure, because of the presence of many scattering centers in polyatomic molecules as well as in the neighborhood of molecules in the condensed phase, ${ }^{49-51}$ making the experimental study of the liquid structure difficult.

Molecular dynamics and Monte Carlo simulations ${ }^{52}$ have been widely used to investigate the properties of liquids. Knowledge about the structure, solvent effects, making and breaking structure effects, H-bonds and other details of the liquids have emerged from these studies. In the present paper, the results obtained with Monte Carlo simulations for both liquids were analyzed. The theoretical $\mathrm{g}(\mathrm{r}) \mathrm{s}$ obtained in this work were compared with those obtained from neutron diffraction with isotopic substitution experiments ${ }^{53-57}$ using an empirical potential structure refinement (EPSR) approach. ${ }^{58-62}$ EPSR is capable of filling in the gaps of missing structural information by imposing reasonable constraints on atomic overlap and on the likely molecular geometries. By comparing the empirical potential and the data directly in the reciprocal space of the measurements, one has the best chance of avoiding the spurious structures and conclusions that might be generated by systematic effects in the data (such as inelasticity effects with neutron scattering or Compton scattering with X-rays). ${ }^{33}$

\section{Methodology}

Molecular models and intermolecular potential function

Optimized potentials for liquid simulations (OPLS-AA) type potentials were used for ACT and NMF. The NMF parameters were optimized in our laboratory, ${ }^{13}$ and the ACT parameters were those optimized by Ferrario et al.$^{23}$ Table 2 
shows the potential parameters for each one. The molecular geometries used were those reported previously. ${ }^{13,33}$ Both liquids were simulated as rigid molecules; therefore, contributions from intramolecular relaxation effects were not considered, an approach customarily used in simulations of molecular liquids.

Table 2. Intermolecular potential parameters for the molecules studied in this work

\begin{tabular}{lccc}
\hline Atoms & $\mathrm{q} / \mathrm{e}$ & $\sigma / \AA$ & $\varepsilon /\left(\mathrm{kcal} \mathrm{mol}^{-1}\right)$ \\
\hline $\mathrm{C}$ & \multicolumn{4}{c}{$\mathrm{N}$-methylformamide } \\
$\mathrm{O}$ & 0.340 & 3.750 & 0.105 \\
$\mathrm{H}(\mathrm{C})$ & -0.460 & 2.960 & 0.210 \\
$\mathrm{~N}$ & 0.120 & 2.750 & 0.038 \\
$\mathrm{C}(\mathrm{Me})$ & -0.700 & 3.250 & 0.140 \\
$\mathrm{H}(\mathrm{N})$ & 0.105 & 3.200 & 0.050 \\
$\mathrm{H}(\mathrm{Me})$ & 0.415 & 0.000 & 0.000 \\
\hline & 0.060 & 2.350 & 0.017 \\
\hline $\mathrm{C}$ & \multicolumn{2}{c}{ Acetone } \\
$\mathrm{O}$ & 0.566 & 3.750 & 0.105 \\
$\mathrm{C}(\mathrm{Me})$ & -0.502 & 2.960 & 0.210 \\
$\mathrm{H}(\mathrm{Me})$ & -0.032 & 3.880 & 0.182 \\
\hline
\end{tabular}

Following the usual procedures in force field calculations, the molecules were modeled with collections of interacting sites and the energy $\mathrm{E}_{\mathrm{ab}}$ between molecules $\mathbf{a}$ and $\mathbf{b}$, represented by the sum of the Coulomb and Lennard Jones potentials centered on the sites:

$E_{a b}=\sum_{i j}\left[\frac{A_{i j}}{r_{i j}{ }^{2}}-\frac{B_{i j}}{r_{i j} 6}+\frac{q_{i} q_{j}}{r_{i j}}\right]$,

where rij is the distance between site $\mathrm{i}$ in $\mathbf{a}$ and site $\mathrm{j}$ in $\mathbf{b}$ and $q i$ and qj are fractional charges located in the $i$ and $j$ molecular sites. For each site k, the parameters Akk and Bkk were given by $\mathrm{A}_{\mathrm{kk}}=4 \varepsilon_{\mathrm{k}} \sigma_{\mathrm{k}}{ }^{12}$ and $\mathrm{B}_{\mathrm{kk}}=4 \varepsilon_{\mathrm{k}} \sigma_{\mathrm{k}}{ }^{6}$, where $\varepsilon_{\mathrm{k}}$ and $\sigma_{\mathrm{k}}$ are the Lennard-Jones parameters for the kth site. Parameters $\mathrm{A}_{\mathrm{ij}}$ and $\mathrm{B}_{\mathrm{ij}}$ for non-diagonal interactions $[i, j]$ were obtained using the geometric combining rules $A_{i j}=\left(A_{i i} A_{j j}\right)^{1 / 2}$ and $B_{i j}=\left(B_{i i} B_{j j}\right)^{1 / 2.52}$

\section{Monte Carlo simulations}

The simulations were carried out in the NPT ensemble at $298 \mathrm{~K}$ and $1 \mathrm{~atm}$, with Metropolis importance sampling and periodic boundary conditions ${ }^{63}$ on systems consisting of a cubic box containing 400 molecules. In calculating the total configurational energy using equation 1, a full intermolecular interaction was considered whenever the rij site-to-site distance was inside a cutoff radius of $11 \AA$. Lennard-Jones potential contributions due to interactions beyond the cutoff radius were calculated using the formalism presented elsewhere. ${ }^{52}$ Several methods have been used to take into account long-range Coulombic interactions. In the present calculations, these interactions were not considered beyond the cutoff radius. The reasons supporting this decision have been discussed previously. ${ }^{64,65}$ Such an approach is further justified taking into account that the molecular potential parameters are effective pair potentials, optimized at the same computational conditions of the simulations themselves. Therefore, they are a kind of mean force parameter that carries out information on Coulombic long-range corrections, many-body effects, molecule polarization and so on. In good agreement with this approach, the site-site pair correlations, thermodynamic properties and single particle dynamics of polar liquids have been reported to be quite insensitive to the long-range forces in the system. ${ }^{66}$

Starting from the initial distribution of molecules in the central box, new configurations were generated by randomly translating and rotating a randomly chosen molecule along Cartesian co-ordinates. As the calculations were carried out in the NPT ensemble, new configurations were also generated through volume changes. A volume movement was tried on every 500th attempted molecular move. After the volume changes, the coordinates of the center of the mass of all molecules in the reference box were scaled in the usual way. ${ }^{52}$ Ranges for translating and rotating the molecules and for volume moves were adjusted to yield an acceptance/trial ratio between 0.40 and 0.45 for new configurations. Each calculation started with an equilibration phase with $2.4 \times 10^{7}$ configurations, and the averages were then obtained after a new segment with other $2.4 \times 10^{7}$ configurations. Statistical uncertainties were calculated from separate averages over blocks of $2.0 \times 10^{5}$ configurations.

\section{Results and Discussion}

\section{N-Methylformamide}

To analyze the data, $g(r)$ curves for some of the NMF site-site correlations obtained in the present work are plotted in Figure 1, and compared to the same plots obtained from the neutron diffraction with isotopic substitution and EPSR simulations, reported previously. ${ }^{13} \mathrm{~A}$ comparison of the curves clearly indicates that the NMF model used in the present simulations has a great ability to reproduce 
the structure of the liquid, even though the experimental results show that in the liquid the atoms are, in fact, a little closer together than in the model. However, the differences are, for all practical purposes, negligible. Although EPSR provides a model that is consistent with the measured diffraction data, it does not necessarily provide the only possible interpretation of the experimental data. ${ }^{50,51,56}$ Thus, obtaining a fit to the measured data does not ensure the potential model is correct, but it is a necessary condition for any chosen potential model of the liquid. However, the theoretical values obtained for the enthalpy of vaporization and the density of the liquid show a good agreement with the experimental values (the theoretical values obtained in the simulations are, respectively, $13.72 \pm 0.01 \mathrm{kcal} \mathrm{mol}^{-1}$ and $1.000 \pm 0.007 \mathrm{~g} \mathrm{~cm}^{-3}$ ), showing that the theoretical model not only is able to give a reasonable average distribution of the molecules but also represents the interactions between them with a good approximation.

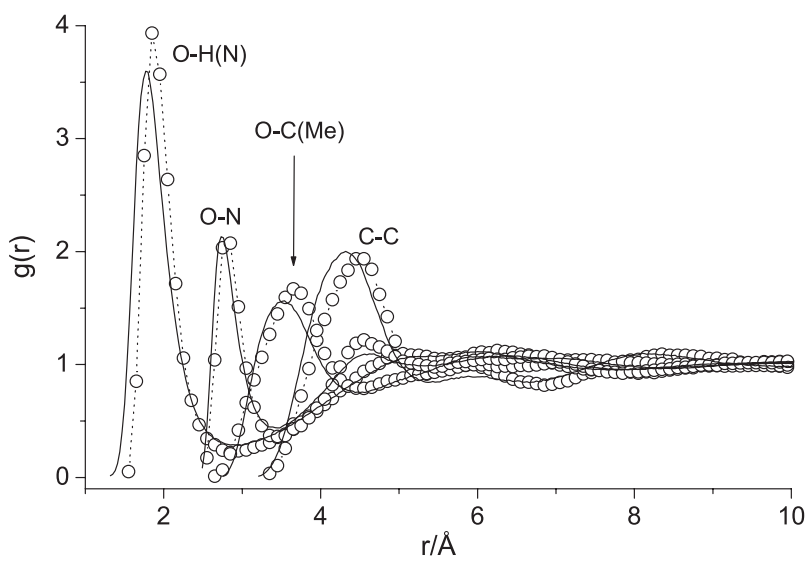

Figure 1. Site-site radial distribution functions derived with EPSR calculations (lines) and Monte Carlo simulations (circles) for NMF. H(N) is the hydrogen bonded to nitrogen, and $\mathrm{C}(\mathrm{Me})$ is the methyl carbon.

As already discussed, the peaks are sharp and well defined at relatively low values of $r$, which suggests that the NMF is highly ordered in the liquid phase. ${ }^{13}$ The presence of the narrow peak of the $\mathrm{O}-\mathrm{H}(\mathrm{N})$ correlations at about $1.8 \AA$ is a strong indication of H-bond linkage between the molecules. Moreover, the peak of the $\mathrm{O}-\mathrm{N}$ correlation at about $2.8 \AA$ points to an alignment of the $\mathrm{O}-\mathrm{H}(\mathrm{N})-\mathrm{N}$ atoms (since the $\mathrm{H}(\mathrm{N})-\mathrm{N}$ bond has a length of about $0.96 \AA$ ), another result suggesting H-bonding between the molecules, according to criteria widely used in the study of H-bonds. ${ }^{19}$

Thus, taking into account that from the point of view of the $\mathrm{g}(\mathrm{r})$ plots the model is able to reproduce the structure of the liquid, one may use the liquid simulations to further explore the intermolecular interactions. As a starting point, the pair energy distribution along the simulation pathway for the intermolecular correlations was calculated, and the results are shown in Figure 2.

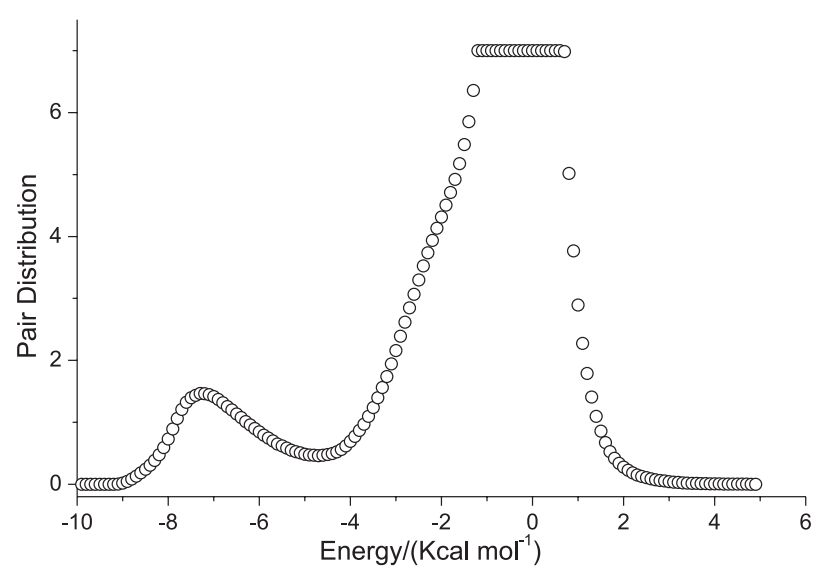

Figure 2. Pair energy distributions derived by the simulation for the NMF molecules in the liquid.

At first glance, the pairwise energy is significantly more negative than for other organic polar liquids, as for instance ethanol, ${ }^{63}$ and the bimodal shape of the curve is characteristic of liquids with $\mathrm{H}$-bonding between the molecules, as previously noticed ${ }^{19,67}$ (the comparison with the curve obtained for acetone, shown later, will better illustrate this point). Thus, there are preponderantly two kinds of molecular correlation, molecules that are hydrogen-bonded to each other and molecules that are correlated through another kind of interaction. This finding points to a well-structured liquid. As the simulated molecular interactions are pairwise interactions, the simulation box was scanned for the most statistically representative dimer in the liquid. Figure 3 shows the species found. Some geometric parameters of that dimer are listed in the figure caption.
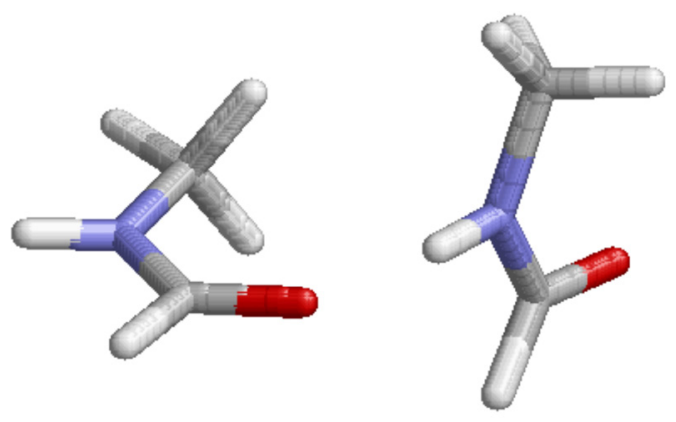

Figure 3. Geometry of the most frequent dimer in the liquid. Angle $(\mathrm{N}-\mathrm{H} \cdots \mathrm{O})=169.0^{\circ}, \mathrm{r}(\mathrm{H} \cdots \mathrm{O})=1.81 \AA, \mathrm{r}(\mathrm{N} \cdots \mathrm{O})=2.76 \AA, \mathrm{r}(\mathrm{C} \cdots \mathrm{C})=4.47 \AA$, $\mathrm{r}(\mathrm{O} \cdots \mathrm{C}(\mathrm{Me}))=3.7 \AA$. $\mathrm{r}(\mathrm{O} \cdots \mathrm{H}(\mathrm{C}=))=3.44 \AA$.

The remarkable agreement between the site-site distances obtained for the dimer and the positions of the corresponding peaks in the $\mathrm{g}(\mathrm{r}$ ) plots (Figure 1) implies that the population of that dimer must be significantly high in the 
liquid. Moreover, the values obtained for the $\mathrm{O} \cdots \mathrm{H}$ distance and the $\mathrm{N}-\mathrm{H} \cdots \mathrm{O}$ angle show a straight agreement with those values usually accepted as characterizing hydrogen bonding: $\mathrm{O} \cdots \mathrm{H}$ distance in the range $c a .1 .2-2.2 \AA$ and the $\mathrm{N}-\mathrm{H} \cdots \mathrm{O}$ angle in the range $c a .130^{\circ}-180^{\circ} .{ }^{19}$ Taking into account these results, the scenario that emerges is that of a liquid with molecules hydrogen bonded to each other, in agreement with what has already been reported before, achieved through other approaches. ${ }^{13}$

The distance $\mathrm{O} \cdots \mathrm{H}(\mathrm{C}=)$ is $3.44 \AA$, which allows this interaction to be attributed to a weak H-bond, according to criteria widely discussed previously. ${ }^{20}$ As has been discussed previously, ${ }^{20}$ this interaction plays an important role in the structure of many biomolecules. Those findings suggest that this interaction might play a significant role in stabilizing the dimer in particular and consequently be important for the liquid structure as a whole. Some aspects of the structure of this dimer, exploited via ab initio calculations, have been discussed in a previous paper. ${ }^{9}$

For a more detailed view of the liquids structure, the molecular dipole-dipole correlation between the molecules was calculated and the $\langle\cos \theta>$ (where $\theta$ is the angle between the molecular dipole moments of the two molecules under consideration) plotted as a function of the distance between the molecules. For the sake of clarity, Figure 4 shows the molecular geometry of both molecules under investigation with the molecular dipole moments drawn on it.
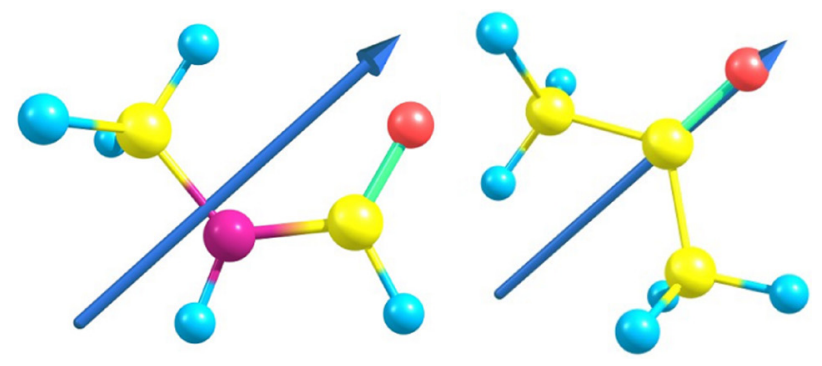

Figure 4. The molecular geometry for NMF (left) and ACT (right), with the molecular dipole moment drawn on the molecules (blue arrow).

In Figure 5, the plot of the $<\cos \theta>$ is shown as a function of the distance between the molecules for NMF. To obtain that, in the computational routine we have to choose an atom in the molecule, as a function of which the distance between the molecules will be computed.

Note that the dipolar correlation follows a pattern that agrees remarkably with the $\mathrm{C}-\mathrm{C}$ correlations in the $\mathrm{g}(\mathrm{r})$ plots (Figure 1); there is a strong dipolar correlation for $\mathrm{C}-\mathrm{C}$ distances in the range of about 3-5 $\AA$, with the molecules oriented in such a way that the molecular dipoles have an angle of about $73^{\circ}$ with each other. There is agreement between this angle and the angle between the molecules

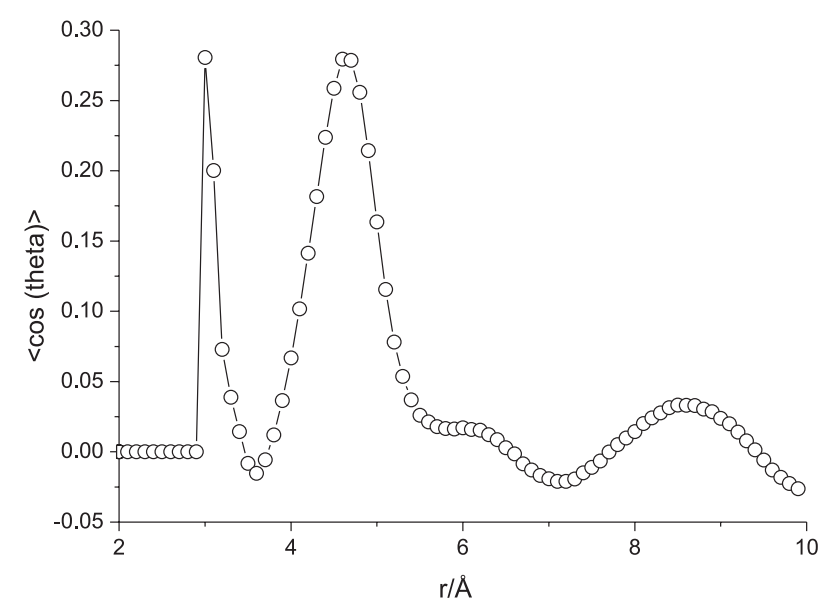

Figure 5. Average dipole-dipole correlation as a function of the carboncarbon distance. Theta is the angle between the dipole moments of the two NMF molecules considered.

of the dimer shown in Figure 3. However, as pointed out previously ${ }^{63}$ the curve shows a bimodal shape, the same pattern also observed for the pair distribution energy shown in Figure 2, which is a characteristic of H-bonding liquids. At larger distances, the molecules adopt more of a perpendicular configuration.

\section{Acetone}

In this section, the paper will follow the same general presentation as for NMF. As the first step, $g(r)$ curves for some of the ACT site-site correlations obtained in the present work are plotted in Figure 6, and compared to the same plots obtained from the neutron diffraction with isotopic substitution studies, reported previously. ${ }^{33}$

The agreement between the experimental and the theoretical results does not have the same quality as that shown by the NMF theoretical model, but on average, the agreement is satisfactory. The theoretical model fails to represent the finer structure of the liquid, responsible for the shoulders verified in the experimental curves; however, the differences are sufficiently negligible to expect that the results obtained from the simulations might be in good agreement with the liquid behavior. The discussion of NMF concerning the limitations of the EPSR simulation in giving the correct structure of the liquids should be remembered. In agreement with what was discussed there, the theoretical values obtained for the liquid density and the heat of vaporization are $0.776 \pm 0.006 \mathrm{~g} \mathrm{~cm}^{-3}$ and $7.74 \pm 0.01 \mathrm{kcal} \mathrm{mol}^{-1}$, respectively).

Thus, considering that the model is able to reproduce the structure of the liquid in a good approximation, the simulations are useful for further exploring intermolecular interactions. As was done above, let us start by analyzing 


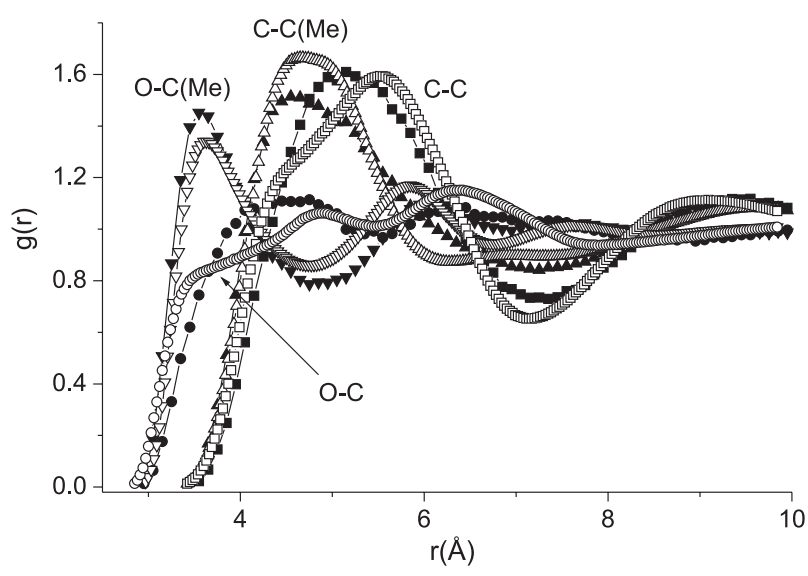

Figure 6. Site-site radial distribution functions derived by the EPSR calculations (empty) and by Monte Carlo simulations (fill) for ACT. $\mathrm{C}(\mathrm{Me})$ is the methyl carbon.

the pair energy distribution along the simulation pathway for the intermolecular correlations; the results are shown in Figure 7. The energy distribution is narrower and the most stable molecular correlations are not as attractive as for NMF, since the interaction energy in ACT is less negative. The humps on the left slope suggest that the molecules are correlated through the liquid bulk in somewhat different ways, which directly agrees with the characteristics of the bands seen in the $\mathrm{g}(\mathrm{r})$ plots (Figure 6).

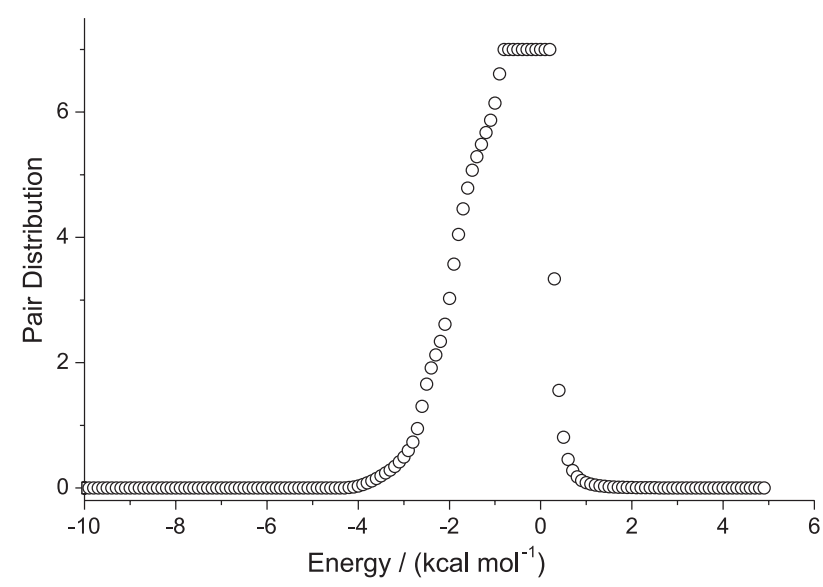

Figure 7. Pair energy distributions derived by the simulation for the ACT molecules in the liquid.

The results strongly suggest a not very highly ordered liquid. The lack of any band in the range of energies below $-4 \mathrm{kcal} \mathrm{mol}^{-1}$ should be noted, in contrast to what was observed for the NMF case. Due to this behavior, scanning the simulation box for the most representative dimers is not suitable, since there would be no strongly predominant dimer in the liquid but rather a collection of randomly distributed dimers. That behavior is clearly reflected in the form of the curve of the dipole-dipole correlation between the molecules as a function of the $\mathrm{C}-\mathrm{C}$ distance shown in Figure 8 (see Figure 4 for an idea of the molecular dipole position). A much broader band than that presented by NMF can be observed, a clear consequence of the spread in the molecular correlations. Thus, instead of looking for the most representative dimer in the liquid, we looked for representative dimers constraining the $\mathrm{C}-\mathrm{C}$ distances to well-defined short ranges. Six dimers were collected, one for each of the ranges shown in Table 3, with the respective angle between the dipole moment for each one. For the sake of illustration, Figure 9 shows the drawings of the first 4 of those dimers.

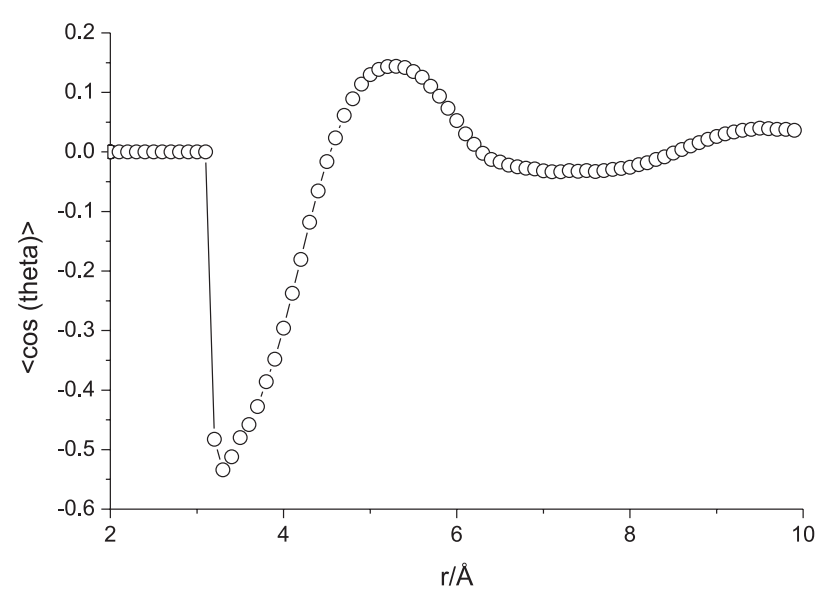

Figure 8. Average dipole-dipole correlation as a function of the carboncarbon distance. Theta is the angle between the dipole moments of the two ACT molecules considered.

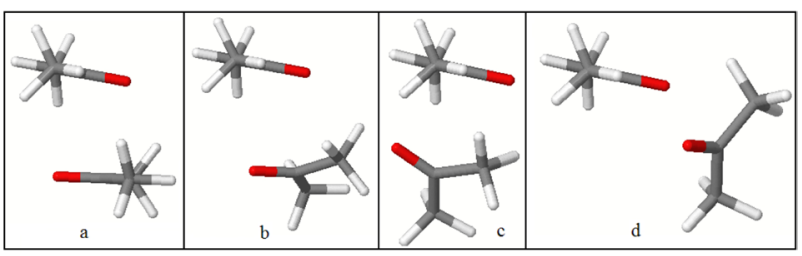

Figure 9. Geometries of ACT dimers as a function of the $\mathrm{C}-\mathrm{C}$ distance. Dimers a, b, c, and d correspond to the C-C distances listed in the four right columns of Table 3, respectively. Molecules drawn with Jmol. ${ }^{68}$

The data analysis shows that the molecules get an antiparallel dipolar correlation at short distances, while when the distance between the molecules is enlarged they tend more to parallel alignments of the molecular dipole

Table 3. Angles between the dipole moments for the ACT-ACT dimers obtained from the simulations at the $\mathrm{C}-\mathrm{C}$ distances

\begin{tabular}{lcccccc}
\hline Distance / $\AA$ & $4-5$ & $4.5-5.5$ & $5-6$ & $5.5-6.5$ & $6-7$ & $6.5-7.5$ \\
\hline Angle / degrees & 172.0 & 160.0 & 156.5 & 130.0 & 106.0 & 45.0 \\
\hline
\end{tabular}


moments. This behavior is characteristic of liquids in which the molecular correlation is dipole orientated. That is exactly the behavior found with neutron diffraction, ${ }^{33}$ and this agreement is a consequence of the ability of the molecular model to represent the liquid structure.

\section{Conclusions}

The structure of the liquids NMF and ACT has been revisited via Monte Carlo simulations in the NPT ensemble. The liquids are popular solvents for many organic processes; moreover, NMF has been of great interest due to the presence of the peptide bond in its structure. Thus, detailing the structure of these liquids is useful for studying the behavior of the peptides in non-aqueous medium. Both liquids were simulated through an all-atom OPLS type potential. As the first step, the theoretical $\mathrm{g}(\mathrm{r}) \mathrm{s}$ of the liquids were compared with those obtained from neutron diffraction and EPSR simulations to estimate the quality of the empirical potentials used. The comparison shows a good agreement between the theoretical and the experimental results indicating that the molecular models are quite able to mimic liquid behavior. The results point to the important role played by the H-bonds driving the NMF liquid structure, while in ACT the correlations are dipole moment oriented. Accordingly, the calculated intermolecular interaction energy is much more negative in NMF than in ACT. This scenario shows a perfect agreement with the liquid properties listed in Table 1. The structure of the liquid NMF is highly ordered and is preponderantly oriented by a dimer, whose molecules are arranged in such a way that the angle between its dipole moments is $73^{\circ}$. All these results can be useful or must be considered when analyzing the $\mathrm{H}$-bonds formation between residues in peptides and the behavior of those $\mathrm{H}$-bonds in different solvents. ACT, on the other hand, is much less organized, and the orientation of the molecules through the liquid changes from an antiparallel dipolar correlation at short distances to a more parallel alignment of the molecular dipole moments at larger distances. As emphasized in the discussions, the calculated intermolecular interaction energy is much less negative in ACT than it is in NMF, which clearly agrees with the properties reported for the liquid. Since the acetone molecules are weakly correlated with each other but acetone is an H-bond acceptor, it can be a good solvent for H-bond donors, such as NMF. Solvent effects must play an important role in this type of solution.

\section{Acknowledgments}

The authors are very grateful to Sylvia E. McLain for kindly providing the experimental acetone g(r) data. J. M.
M. C. is particularly grateful to FAPESP (Fundação de Amparo à Pesquisa do Estado de São Paulo, Brazil), for supporting a stay at RAL-ISIS (process No. 2007/07513-2).

\section{References}

1. Lide, D. R.; Handbook of Chemistry and Physics, $83^{\text {rd }}$ ed.; Wiley: New York, 2002.

2. Gao, J.; Pavelites, J. J.; Habibollazadeh, D.; J. Phys. Chem. A 1996, 100, 2689

3. Hirst, J. D.; Hirst, D. M.; Brooks, C. L.; J. Phys. Chem. A 1997, $101,4821$.

4. Desfrancois, C.; Periquet, V.; Carles, S.; Schermann, J.P.; Smith, D. M. A.; Adamowicz, L.; J. Chem. Phys. 1999, 110, 4309.

5. Torii, H.; Tasumi, M.; J. Phys. Chem. A 2000, 104, 4174.

6. Headley, A. D.; Nam, J.; THEOCHEM 2002, 589, 423.

7. Nandini, G.; Sathyanarayana, D. N.; THEOCHEM 2002, $579,1$.

8. Martinez, A. G.; Vilar, E. T.; Fraile, A. G.; Martinez-Ruiz, P.; J. Phys. Chem. A 2002, 106, 4942.

9. Cordeiro, J. M. M.; Cordeiro, M. A. M.; Bosso, A. R. S. A.; Politi, J. R. S.; Chem. Phys. Lett. 2006, 423, 67.

10. Cordeiro, J. M. M.; Bosso, A. R. S. A.; J. Mol. Liq. 2010, 154, 36.

11. Hammami, F.; Nasr, S.; Bellisent-Funel, M. C.; J. Chem. Phys. 2005, 122, 1 .

12. Schoester, P. C.; Zeidler, M. D.; Radnai, T.; Bopp, P. A.; Z. Naturforsch., A: Phys. Sci. 1995, 50, 38.

13. Cordeiro, J. M. M.; Soper, A. K.; J. Phys. Chem. B 2009, 113, 6819.

14. Shin, S.; Kurawaki, A.; Hamada, Y.; Shinya, K.; Ohno, K.; Tohara, A.; Sato, M.; J. Mol. Struct. 2006, 791, 30.

15. Neuefeind, J.; Chieux, P.; Zeidler, M. D.; Mol. Phys. 1992, 76, 143.

16. Neuefeind, J.; Zeidler, M. D.; Poulsen, H. F.; Mol. Phys. 1996, $87,189$.

17. Hammami, F.; Nasr, S.; Oumezzime, M.; Cortes, R.; Biomol. Eng. 2002, 19, 201.

18. Sathyanarayana, D. N.; Ganeshsrinivas, E.; Indian J. Chem., Sect. A: Inorg., Bio-inorg., Phys., Theor. Anal. Chem. 2003, 41, 1564.

19. Geffrey, G. A.; An Introduction to Hydrogen Bonding; Oxford University Press: New York, 1997.

20. Desiraju, G. R.; Steiner, T.; The Weak Hydrogen Bond; Oxford University Press: Oxford, 1999.

21. Freitas, L. C. G.; Cordeiro, J. M. M.; Garbujo, F. L. L.; J. Mol. Liq. 1999, 79, 1.

22. Bertagnolli, H.; Hoffmann, M.; Ostheimer, M. Z.; Phys. Chem. 1989, 165, 165.

23. Ferrario, M.; Haughney, M.; McDonald, I. R.; Klein, M. J.; J. Chem. Phys. 1990, 93, 5156. 
24. Cordeiro, J. M. M.; Phys. Chem. Liq. 2007, 45, 31.

25. Richardi, J.; Fries, P. H.; Fischer, R.; Rast, S.; Krienke, H.; Mol. Phys. 1998, 93, 925.

26. Wheeler, D. R.; Rowley, R. L.; Mol. Phys. 1998, 94, 555.

27. Radnai, T.; Bako, I.; Jedlovszky, P.; Palinkas, G.; Mol. Simul. 1996, 16, 345 .

28. Jedlovszky, P.; Palinkas, G.; Mol. Phys. 1995, 84, 217.

29. Weerasinghe, S.; Smith, P. E.; J. Chem. Phys. 2003, $118,10663$.

30. Venables, D. S.; Schmuttenmaer, C. A.; J. Chem. Phys. 2000, $113,11222$.

31. Venables, D. S.; Schmuttenmaer, C. A.; J. Chem. Phys. 2000, 113,3249 .

32. Jorgensen, W. L.; Briggs, J. M.; Contreras, M. L.; J. Phys. Chem. 1990, 94, 1683.

33. McLain, S. E.; Soper, A. K.; Luzar, A.; J. Chem. Phys. 2006, $124,74502$.

34. Soares, C. M.; Teixeira, V. H.; Baptista, A. M.; Biophys. J. 2003, $84,1628$.

35. Clark, D. S.; Phil. Trans. R. Soc. B 2004, 359, 1299.

36. Dordick, J. S.; Biotechnol. Prog. 1992, 8, 259.

37. Halling, P. J.; Curr. Opin. Chem. Biol. 2000, 4, 74.

38. Klibanov, A. M.; Trends Biotechnol. 1997, 15, 97.

39. Halling, P. J.; Phil. Trans. R. Soc. B 2004, 359, 1287.

40. Vidal, M.; Santos, A. M.; Barletta, G.; J. Am. Chem. Soc. 2001, 123, 5380 .

41. Halling, P. J.; Blackwood, A. D.; Moore, B. D.; Ann. N. Y. Acad. Sci. 1996, 799, 251.

42. Colombo, G.; Toba, S.; Merz, K. M.; J. Am. Chem. Soc. 1999, $121,3486$.

43. Klibanov, A. M.; Nature 2001, 409, 241.

44. Peters, G. H.; Van Alten, D. M. F.; Edholm, O.; Toxvaerd, S.; Bywater, R.; Biophys. J. 1996, 71, 2245.

45. Toba, S.; Hartsough, D. S.; Merz, K. M.; J. Am. Chem. Soc. 1996, 118, 6490.

46. Yang, L.; Dordick, J. S.; Garde, S.; Biophys. J. 2004, 87, 812.

47. Cordeiro, J. M. M.; Int. J. Quantum Chem. 2006, 106, 652.

48. Gray, C. G.; Gubbins, K. E.; Theory of Molecular Liquids; Oxford University Press: New York, 1984.

49. Soper, A. K.; J. Phys.: Condens. Matter 1997, 9, 2399.
50. Soper, A. K.; Mol. Phys. 2001, 99, 1503.

51. Soper, A. K.; Phys. Rev. B: Condens. Matter Mater. Phys. 2005, 72, 104204 .

52. Allen, M.; Tildesley, D. J.; Computer Simulation of Liquids; Oxford University Press: Oxford, 1987.

53. Hulme, E. C.; Soper, A. K.; McLain, S. E.; Finney, J. L; Biophys. J. 2006, 91, 2371.

54. Mason, P. E.; Neilson, G. W.; Enderby, J. E.; Saboungi, M. L.; Brady, J. W.; J. Phys. Chem. B 2005, 109, 13104.

55. Mason, P. E.; Neilson, G. W.; Enderby, J. E.; Saboungi, M. L.; Brady, J. W.; J. Phys. Chem. B 2006, 110, 2981.

56. McLain, S. E.; Soper, A. K.; Watts, A.; J. Phys. Chem. B 2006, 110, 21251

57. McLain, S. E.; Soper, A. K.; Terry, A. E.; Watts, A.; J. Phys. Chem. B 2007, 111, 2568.

58. Soper, A. K.; Silver, R. N.; Phys. Rev. Lett. 1982, 49, 471.

59. Botti, A.; Bruni, F.; Imberti, S.; Ricci, M. A.; Soper, A. K.; J. Mol. Liq. 2005, 117, 77.

60. Botti, A.; Bruni, F.; Imberti, S.; Ricci, M. A.; Soper, A. K.; J. Mol. Liq. 2005, 117, 81.

61. Soper, A. K.; Finney, J. L.; Phys. Rev. Lett. 1993, 71, 4346.

62. Soper, A. K.; Luzar, A.; J. Phys. Chem. 1996, 100, 1357.

63. Freitas, L. C. G.; J. Braz. Chem. Soc. 2009, 20, 1541.

64. Israelachvili, J. N.; Intermolecular and Surface Forces; Academic Press: London, 1985.

65. Cordeiro, J. M. M.; Cordeiro, M. A. M.; J. Braz. Chem. Soc. 2004, $15,351$.

66. Ladanyi, B. M.; Skaf, M. S.; Annu. Rev. Phys. Chem., 1993, 44, 335.

67. Jorgensen, W. L.; Maxwell, D. S.; Tirado-Rieves, J.; J. Am. Chem. Soc. 1996, 118, 11225.

68. Jmol: An Open-Source Java Viewer for Chemical Structures in $3 D ;$ http://www.jmol.org.

Submitted: April 3, 2011

Published online: October 4, 2011

FAPESP has sponsored the publication of this article. 